\title{
A luta contra as explorações/opressões, o debate étnico-racial e o trabalho do assistente social
}

\author{
The fight againstfarms/oppressions, the \\ ethnic-racial debate and the work of the social worker
}

Márcia Campos Euricoa

Resumo: $\mathrm{O}$ artigo explicita alguns aspectos da questão étnico-racial no contexto da sociedade brasileira na contemporaneidade e busca apreender como a intervenção protagonizada por várias mulheres negras, ativistas na luta contra o racismo, que ingressaram na profissão, principalmente a partir de 1980, legitima o debate efervescente na vida cotidiana. Apreender as assimetrias de raça/ cor e o modo como o racismo opera é condição primordial para a efetivação do Projeto Ético-Político do Serviço Social.

Palavras-chave: Racismo institucional. População negra. Serviço Social.

\begin{abstract}
The article clarifies some aspects of the ethnic-racial issue in the context of Brazilian society in contemporary and seeks to apprehend as the intervention starring by several black women, activists in the fight against racism, who entered the profession, mainly from 1980, legitimizes the debate, effervescent in everyday life. Apprehending the asymmetry of race/color and the way in which racism operates is a prime condition for the effective ethical-political project of Social services.
\end{abstract}

Keywords: Institutional racism. Black population. Social Services.

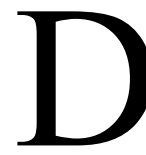

iversas situações de violação dos direitos humanos são reproduzidas no miúdo da vida cotidiana brasileira, a exemplo das condições vexatórias em que sobrevivem parcelas significativas da população, sem acesso aos mínimos sociais, assistidas por políticas sociais fragmentadas, pontuais e focalizadas. Quando se entrecruzam as variáveis classe social, gênero, raça/etnia, a questão da miserabilidade afeta proporcionalmente mais homens e mulheres negras de todas as idades. 
A despeito da concretude das assimetrias de raça/cor no país, somos bombardeadas(os) com discursos e práticas que reatualizam o mito da democracia racial e reivindicam o privilégio de classe, camuflado pela falácia da meritocracia. Há inclusive aqueles(as) que invocam o Artigo $5^{\circ}$ da Constituição Federal vigente para desqualificar lutas e conquistas importantes para o conjunto da sociedade, sob o argumento de que qualquer tratamento diferenciado fere o princípio de que "todos são iguais perante a lei, sem distinção de qualquer natureza".

É fácil reivindicar mérito quando este é sinônimo de privilégio. Fácil levantar a bandeira do mérito quando a vida não está ameaçada de maneira diária, incessante e sem trégua por um Estado facista, racista e homofóbico. Os recentes acontecimentos reavivam em nós o status quo e a dor denunciada por exemplo pelas "Mães de Maio", vozes femininas que insistem em afirmar que "os nossos mortos têm voz". Aqui reverencio homens e mulheres de todas as idades que morreram pelas mãos do Estado brasileiro, pela fome, pobreza, acesso precário à saúde, à moradia, à segurança pública, pela criminalização dos pobres e dos movimentos sociais, pela ação desenfreada das milícias, entre tantas outras expressões violentas da questão social. Mortes que se universalizam nas figuras das Cláudias, Marieles, Luanas, Dandaras, Amarildos, Fabianes... Quero lembrar também o encarceramento em massa da população negra, de maneira tão emblemática quanto o aprisionamento e a condenação por convicção do jovem negro Rafael Braga.

Este é o cenário que conforma a vida da maioria da população negra em um país que completará no próximo dia 13 de maio a marca de 130 anos de abolição da escravidão, sem que mudanças significativas tenham ocorrido na vida cotidiana. No próximo dia 15 de maio será a vez de o Serviço Social completar 82 anos de existência no país, e o material alusivo à data destaca que "Nossa escolha é a resistência: somos classe trabalhadora!".

Quero reafirmar que nosso compromisso com a classe trabalhadora precisa considerar necessariamente suas pautas universais, mas também apreender suas particularidades. Entre o universal e o particular se põe um campo de disputas onde certamente o pertencimento étnico-racial, a 
identidade de gênero, a orientação sexual, o lugar ocupado na divisão social e técnica do trabalho revelam a diversidade humana, mas também acirram a desigualdade no interior da própria classe.

Nas próximas linhas me ocuparei do debate acerca do racismo institucional e do quanto as(os) assistentes sociais podem no seu trabalho cotidiano reproduzir práticas racistas, ainda que de maneira abstrata e no campo das ideias reproduzam o discurso da luta contra todas as formas de opressão.

Certamente esta é uma perspectiva radical, e é a partir dela que quero abrir o debate. $\mathrm{O}$ racismo no que se refere à população negra e aos povos indígenas está enraizado na sociedade brasileira, e as razões pelas quais ele se reatualiza cotidianamente são complexas e contraditórias. Logo, não existe uma única resposta para esta questão, posto que mergulhar nesse terreno acidentado implica adentrar pelo campo da ideologia e da sua funcionalidade em cada período histórico, identificando os sistemas de privilégios dos grupos humanos que reivindicam para si um lugar de superioridade.

O Serviço Social brasileiro enfrenta na década de 1980 os mesmos dilemas postos para a sociedade, no árduo processo de redemocratização do país. Do ponto de vista do debate acerca do racismo, o período também é emblemático, e o avanço da luta contra o preconceito e a discriminação étnico-racial, seja em âmbito nacional, seja internacionalmente, com certeza incide na profisssão. Ora, se o Serviço Social é parte e expressão da sociedade, a intervenção protagonizada por várias mulheres negras, militantes, que ingressaram na profissão tem grande impacto no sentido de ampliar o debate e exigir respostas institucionais acerca do racismo. A partir desta década o coletivo profissional será provocado a repensar suas referências teóricas e ampliar o debate para apreender os desdobramentos do racismo institucional no trabalho profissional.

Destaco a importância dessas mulheres na inserção do debate étnico-racial nas deliberações da categoria profissional a partir das(os) profissionais que integram a gestão do Conselho Federal de Serviço Social no período de 1990 a 1993. Pela primeira vez na história da profissão, a questão da não discriminação aparece como um dos princípios fundamentais do Código de 
Ética Profissional do(a) Assistente Social, aprovado em 1993. Deve-se destacar que a trajetória das mulheres negras, assistentes sociais, que travaram batalhas importantíssimas e abriram caminho para o debate étnico-racial no espaço acadêmico, a partir da década de 1980, ainda carecem de um registro rigoroso, que nos permita compreender melhor o debate no interior da profissão naquele período.

Um marco importante da luta contra o racismo e que merece destaque é o processo de organização da fase preparatória para a III Conferência Mundial contra o Racismo, a Discriminação Racial, a Xenofobia e todas as Formas Correlatas de Intolerâncias (2001) realizada na cidade de Durban, África do Sul, espaço onde se discutiu o respeito aos direitos humanos e às liberdades fundamentais para todos, sem qualquer tipo de distinção. O documento final da conferência apresenta, desde os preâmbulos, a reafirmação dos princípios de igualdade e não discriminação, reconhecidos na Declaração Universal de Direitos Humanos. O racismo que incide sobre a população negra em esfera global foi alvo de críticas contundentes. No âmbito nacional, as deliberações são inseridas nas agendas dos movimentos sociais envolvidos na luta contra o preconceito, a discriminação étnico-racial, a xenofobia, a intolerância religiosa, evidenciando a urgência da aplicação de medidas que visem coibir práticas violadoras dos direitos humanos.

A partir de então a questão étnico-racial ganha visibilidade na cena política e passa a ser reconhecida e tratada pelo Estado brasileiro como um problema nacional, momento em que se desenvolve o Programa de Combate ao Racismo Institucional no país, com a finalidade de contribuir com o estabelecimento de políticas de desenvolvimento e redução da pobreza, bem como combater as desigualdades decorrentes da origem étnico-racial das(os) brasileiras(os).

A participação ativa de diversos segmentos do movimento negro e de agentes públicos, com experiência em relação ao tema, foi crucial no processo de denúncia das situações de racismo, preconceito e discriminação étnico-racial vivenciadas pela população negra no âmbito da vida privada. Para além dessas situações, os diversos sujeitos coletivos denunciaram o 
tratamento discriminatório no acesso aos bens e serviços e às várias políticas públicas promovidas pelas próprias instituições e que mantêm a reprodução da pobreza geracional e de mecanismos de permanência da população negra nas áreas de maior vulnerabilidade econômica, política, social, bem como a desqualificação de sua cultura e práticas religiosas.

Seguramente, os debates protagonizados pelas(os) profissionais engajadas(os) na luta antirracista e que desenvolvem seu trabalho profissional como assistentes sociais representam um marco, à medida que permitem desvelar as determinações presentes na vida social e que requerem outras mediações que permitam a análise do movimento do real, naquilo que representam as particularidades da população negra brasileira.

Os avanços continuam, e a tarefa que se coloca como urgente é desvendar nas tramas do real a intrínseca relação entre questão étnico-racial e questão social, à luz da teoria marxista, ação que não se coloca apenas como modismo, como tarefa particular de assistentes sociais negras(os), mas como uma imperiosa tarefa do coletivo profissional, à medida que a fragmentação da análise pode produzir pesquisas e intervenções no âmbito das políticas públicas, com um cariz de modernidade, mas apoiadas em posturas conservadoras e autoritárias.

Na contemporaneidade, a hierarquização dos grupos étnico-raciais, a partir do padrão da branquitude, tem sido funcional aos interesses do capitalismo. O conceito de branquitude vem sendo debatido com densidade teórica por Schucman (2014), o que nos permite apreender o "ser branco" como alguém que ocupa determinadas posições e lugares sociais vinculados, no caso da experiência brasileira, à aparência, ao status e ao fenótipo. Schucman (2014) afirma que do mesmo modo que as categorias de classe e gênero, "a categoria raça é um dos fatores que constitui, diferencia, hierarquiza e localiza os sujeitos em nossa sociedade" (p. 85). Neste sentido, podemos tomar como base o lugar do belo no imaginário social a partir da branquitude. Por conseguinte, a "superioridade estética é sim um dos traços da branquitude em nosso país" (p. 90) e se desenvolve em relação a todos os outros, não brancos. 
Iraci e Sovik (2004) vão além e referem que a branquitude e seu sistema de privilégios não se restringe à cor da pele, mas funciona como uma espécie de passaporte, que possibilita o acesso a lugares diferenciados, o que se pode perceber entre as pessoas cuja herança genética é atribuída à população negra, mas que, ao exibir fenótipos próximos aos brancos, como, por exemplo, traços mais "finos", podem ser tratadas como "brancas".

A escolha metodológica de iniciar o debate pautando a questão da branquitude tem como finalidade considerar, a priori, que nunca houve, não há e jamais haverá racismo reverso. Ao afirmar isto, busco apreender a questão da branquitude no âmbito das construções sócio-históricas e desnaturalizar o lugar do privilégio, no interior de uma sociedade patriarcal, machista, racista e sexista. Para tanto faz-se necessário superar um modo de vida em que as diferenças e os privilégios, segundo raça/cor, são potencializados. Retomando Schucman, "é preciso que a branquitude, como lugar de normatividade e poder, se transforme em identidades étnico-raciais brancas em que o racismo não seja o pilar de sustentação" (2014, p. 92).

O racismo é um fenômeno universal que, no caso do Brasil, incide majoritariamente sobre a população negra e tem como uma das formas mais eficazes de opressão a desqualificação de tudo aquilo que remete a sua herança genética, cultural, religiosa, a suas tradições e valores, quando estes colocam em jogo a supremacia branca. Há, no entanto, a apropriação de alguns símbolos do grupo e uma valoração positiva a partir da análise do grupo dominante, com o intuito de promover a harmonia social. Com frequência podemos encontrar a valorização de objetos/adornos específicos, o que nem de longe é sinônimo de valorização da própria população negra.

Essa inversão apoia-se no racismo, um sistema de opressão estruturado a partir de relações de poder. Ainda que, no âmbito individual, uma pessoa do grupo dito "inferior" consiga superar o grupo dito "superior", isto não altera substantivamente a noção coletiva da hierarquização das raças e da "inferioridade".

A tese pseudocientífica de que a população negra era naturalmente inferior há muito foi derrubada. Entretanto, o racismo se mantém porque 
cumpre uma função social, na qual a supremacia da branquitude continua a autorizar a exploração, a dominação e a opressão contra os outros. Por outro lado, as pesquisas com seres humanos avançaram de maneira significativa nas últimas décadas, evidenciando a proximidade genética entre grupos cujas características físicas são absolutamente distintas. Entretanto, a objetividade da ciência, em vez de solucionar velhos dilemas, nos coloca novos desafios e reforça nossa indignação com os casos de racismo, preconceito e discriminação étnico-racial reproduzidos diariamente nos mais diferentes espaços e classes sociais.

Ora, os estudos genéticos comprovaram que não existem raças puras, que indivíduos pertencentes a grupos diversos, com características físicas distintas, podem ser biologicamente muito próximos. Se nossa constituição genética pode ser tão próxima, ao mesmo tempo que nossa aparência física pode ser tão distante, como explicar a reprodução "viral" do racismo ao longo da história?

Raça é um conceito elástico que se modifica conforme as demandas históricas e pode ser utilizado igualmente tanto por defensores da ideologia racial, quanto por seus adversários. Essa elasticidade, não raramente, traz como resultado a indiferença quanto a um problema social tão complexo conforme Santos (1984). Portanto, mesmo que eu compartilhe dessa ideia, de que o conceito não se sustenta a partir do biológico, o debate sobre raça não é uma falsa questão, uma vez que os grupos raciais constroem concepções acerca dos outros grupos raciais, no intuito de marcar a diferença e a hierarquia.

A hierarquia tem sua gênese no processo de escravidão no Brasil, um fenômeno historicamente determinado e datado, ancorado na supremacia branca, e que se organiza a partir de uma estrutura que, pela primeira vez na história da humanidade, submete à escravização um grupo inteiro em virtude da sua origem étnico-racial negra, a partir do século XVI. O tráfico transatlântico de seres humanos do continente africano para o Brasil, no espectro da colonização portuguesa, é parte de um projeto maior, devido à necessidade de um contingente enorme de mão de obra altamente qualificada 
para desbravar um território tão extenso. São homens e mulheres negros detentores de saberes na área da agricultura, da fundição de ferro, extração de minérios, entre outros, que são arrancados do continente africano, perdem sua identidade, são batizados com nomes de santas e santos católicos, para ser imediatamente transformados em mercadoria. Mais que o suor do trabalho forçado, a capacidade intelectual é que agrega valor a essa mercadoria desumanizada para que não seja necessário o exame de consciência da classe dominante acerca da barbárie que o processo de escravização da população negra reatualiza. Afinal, a burguesia vive da exploração do trabalho.

Minha investigação parte da premissa que há entre o racismo e o capitalismo uma articulação fortalecida pela ideologia racial, essencial para a dinâmica das relações sociais na contemporaneidade e que justifica, ainda que não explique, o pauperismo de parcela majoritária da população negra brasileira. A permanência histórica desse grupo em patamares vexatórios e a forma como as políticas públicas vêm se desenvolvendo sob o mito da democracia racial leva a uma pretensa inclusão dos diferentes no acesso aos bens e serviços, cunhada pelo discurso da igualdade jurídica.

O tratamento autoritário e racista com que o Estado brasileiro trata as questões relativas à população negra na contemporaneidade está atrelado ao projeto societário em curso e guarda profunda relação com o lugar da "inferioridade" a que a população negra vem sendo submetida desde o período colonial. Com frequência, os detentores dos meios de produção a excluem das funções que exigem níveis altos de qualificação técnica e restringe seu acesso às vagas consideradas mais "simples", por acreditarem que existe uma incompatibilidade entre ser negro e ser capaz de exercer atividades que demandam certo grau de desenvolvimento intelectual, reproduzindo a lógica da separação entre trabalho manual e intelectual.

Sob tais bases, o trabalho manual se acopla à "incapacidade" da população negra. E, no interior da classe trabalhadora, há níveis diferentes de exploração da mão de obra, segundo o pertencimento étnico-racial, ou seja, quanto mais escura a cor da pele, mais as ofertas de trabalho serão precarizadas e desprotegidas, e as remunerações não permitem a manutenção de patamares 
mínimos de existência. As funções mais precarizadas, que se assemelham àquelas desenvolvidas durante a escravidão, são "naturalmente" reservadas para esse grupo, uma vez que permanece a reprodução da "inferioridade" étnico-racial da população negra. Em relação ao trabalho doméstico, não é por acaso que este é desenvolvido majoritariamente por mulheres negras, pois exige baixa escolaridade, pouca qualificação técnica e alta capacidade de resistência, quer do ponto de vista da força física, quer da condição de subalternidade, em um cenário de "afetividade" entre patrões e empregadas.

Angela Davis, no livro Mulheres, raça e classe, aborda a questão das diversas opressões que estruturam a sociedade capitalista, em especial nos Estados Unidos da América, mas sua análise tem muito a contribuir com os debates ao redor do mundo, sobre as faces excludentes do capitalismo, inclusive em relação ao modo pelo qual o racismo se sobrepõe à solidariedade de classe entre as(os) trabalhadoras(es) e, é essencial, entre as mulheres de diversas origens. As estratificações no interior da classe trabalhadora estão marcadas pelo racismo, com rebatimento, inclusive, entre homens e mulheres de origem branca.

As(os) assistentes sociais desenvolvem seu trabalho profissional nas diversas políticas públicas, no complexo e contraditório processo de reprodução das relações sociais. No modo de produção capitalista, a manutenção de níveis extremos de desigualdade social está mediada pela funcionalidade do racismo e, no caso das relações institucionais, sejam elas públicas ou privadas, é dependente do racismo institucional, que possibilita a manutenção de práticas racistas, internalizadas e reproduzidas de maneira automatizada e naturalizada.

O racismo institucional refere-se às operações anônimas de discriminação racial em instituições, profissões ou mesmo em sociedades inteiras, de acordo com Cashmore et al. (2000). O anonimato existe na medida em que o racismo é institucionalizado, perpassa as diversas relações sociais, mas não pode ser atribuído ao indivíduo isoladamente. Ele se expressa no acesso à escola, no mercado de trabalho, na criação e implantação de políticas públicas que desconsideram as especificidades raciais e na reprodução 
de práticas discriminatórias arraigadas nas instituições, conforme descrito por Eurico (2011).

Em Lopes e Quintiliano (2007) vemos que no âmbito institucional — onde se desenvolvem as políticas públicas, os programas e as relações interpessoais - , toda vez que a instituição não oferece acesso qualificado às pessoas em virtude de sua origem étnico-racial, da cor da sua pele ou cultura, o trabalho fica comprometido, o que se configura como racismo institucional.

Nas últimas duas décadas, as discussões sobre como o setor público poderia comprometer-se mais efetiva e continuadamente com a prevenção e o combate ao racismo institucional, no âmbito público e privado, desencadearam uma série de ações, com destaque para a proposta coordenada pelo Instituto Amma Psique e Negritude (2008) com o título Identificação e abordagem do racismo institucional, cuja análise aponta duas dimensões interdependentes e correlacionadas: a dimensão político-programática e a dimensão das relações interpessoais.

O racismo institucional se expressa no modo como as instituições estabelecem suas diretrizes gerais, as relações de poder, como são reproduzidas ações pragmáticas, sustentadas pelo mito da democracia racial, e as(os) profissionais precisam se apropriar do debate para que consigam fortalecer a resistência diante dessas estruturas de poder, inclusive no estabelecimento das relações interpessoais, que sofrem interferências institucionais, sendo que em várias situações a atitude individual extrapola os limites institucionais, desconsiderando princípios fundamentais baseados na ética e no respeito ao outro. Entendemos que no cotidiano das instituições, no qual o racismo se revela de maneira constante e sem tréguas, as(os) assistentes sociais podem assumir o compromisso de desvelar o racismo na dimensão organizacional, propor intervenções na direção oposta e desempenhar papel relevante também no trabalho com a equipe para coibir práticas racistas, que incidem de maneira perversa na vida da população negra.

Destaco como uma ação importante para as(os) assistentes sociais na luta contra o racismo o tratamento adequado dos indicadores sociais e a qualificação desses dados, posto que pela nossa "fama" recentemente fomos 
inseridas indiscriminadamente como "peritas(os)" em equipes responsáveis pela avaliação de fenótipo para o acesso às cotas para negras(os) em concursos públicos, e somos consultadas também em relação aos critérios de autoclassificação no acesso às cotas nas universidades públicas.

É preciso aprofundar o debate para não incorrer em erros grosseiros, a partir da reprodução de discursos vazios e estéreis acerca de uma questão tão cara para a sociedade brasileira. Há que se pensar em qualificação profissional com envolvimento do conjunto CFESS/Cress, Abepss e Enesso, uma vez que a apreensão das determinações sócio-históricas que conformam a presença negra no país é fator primordial para que o atendimento dispensado pela(o) assistente social se efetive com base nos princípios que norteiam o trabalho profissional, independente da área de atuação.

Diversos estudos, seguindo a metodologia do próprio Instituto Brasileiro de Geografia e Estatística - IBGE (2010), apresentam os dados referentes ao quesito cor/raça, agregando pretos e pardos em um mesmo indicador, já que estes compõem a população negra. Nossa análise partilha dessa interpretação, pois ainda que muitas pessoas não se reconheçam como pretas e se autodeclarem pardas, estas serão alvo do acesso precário às políticas públicas, tanto quanto as primeiras, quando comparadas a outros grupos raciais. Entretanto, há que se problematizar o fato de diversos instrumentais de coleta de dados, pesquisas acadêmicas e produções teóricas reproduzirem reiteradamente graves erros analíticos, ora classificando a população negra como negra e parda, ora como negra e mulata, ora como negra e preta, ora como preta e mestiça, entre outras variações presentes no imaginário social brasileiro. Mesmo quando se trata de trabalhos com reconhecida qualidade teórica, a confusão quanto aos termos e a falta de uniformidade no uso das classificações adotadas pelo instituto, e que são utilizadas por vários institutos de pesquisa, trazem prejuízos ao debate, reforçando aquilo que sistematicamente tenta se combater: o racismo institucionalizado e inquestionável, de tão naturalizado.

Em última análise, o uso de terminologias diversas, conflitantes entre si, também cumpre o papel de reprodução do racismo institucional, à medida 
que seus interlocutores podem construir respostas falseadas para problemas reais. Preta e parda, entendidas como cores, correspondem às construções sociais, assim como as outras categorias, e o IBGE as adota para classificar a população negra no Brasil. A uniformização das cores é relevante, pois permite que as desigualdades étnico-raciais possam ser comparadas em diversas pesquisas de instituições diferentes. Se conhecer a população negra é fundamental, o uso de terminologias variadas e divergentes é um complicador. Nas últimas décadas, essa pauta tem sido ampliada, como resultado da maior visibilidade política que esse segmento alcançou, problematizando aquelas formas de identificação que eram historicamente pejorativas e que incidiram na formulação de qualificadores condizentes com o país.

Assim, a alta concentração da população na categoria parda, quando se analisa pretos e pardos, revela o longo caminho a ser trilhado rumo à consciência do pertencimento étnico-racial, reduzindo as barreiras da cor, pois há, entre os brasileiros, uma falsa ideia de que preta é uma categoria pejorativa - leia-se: feia. Então, uma parcela significativa da população negra vive um doloroso dilema: valorizar a herança africana, ao mesmo tempo que anseia por determinado status social obtido pela aproximação do grupo racial branco e pela negação da sua própria negritude.

O racismo institucional determina, antes mesmo do nascimento, o lugar de classe, no interior da própria classe trabalhadora, segundo critérios de raça/cor, com raríssimas exceções. E aqui vou me valer de uma constatação precisa do racismo nos escritos de Carolina Maria de Jesus, no livro Quarto de despejo: "Eu escrevia peças e apresentava aos donos de circos. Eles respondiam-me: - É pena você ser preta" (Jesus, 1960, p. 90).

A coleta do quesito raça/cor apresenta-se fetichizada no trabalho profissional das(os) assistentes sociais, que, ao se depararem com a pergunta, não sabem como encaminhar a questão. O preenchimento desse dado requer uma análise acerca do véu que separa a(o) profissional e a população atendida. Não fosse a incidência do racismo entre nós, perguntar a cor seria simplesmente classificar os sujeitos e a partir daí identificar a maior ou menor capacidade de cobertura dos diversos grupos étnico-raciais pelas políticas públicas. 
Em uma sociedade racista ocorre exatamente o oposto, e a coleta do quesito raça/cor faz emergir o mito da democracia racial e a turbulência provocada pelo racismo real, persistente e arraigado, ofuscado pelo discurso da igualdade. Chamo a atenção para isso porque têm sido recorrentes estudos que analisam raça/cor somente quando as pesquisas se referem à população negra, quando este deve ser um qualificador universal, que permite, nas pesquisas com outros grupos populacionais, apresentar a partir da raça/cor o lugar de maior ou menor privilégio de cada grupo.

E por fim e sem esgotar o debate é importante explicitar que as marcas e rupturas provocadas pelo racismo no Brasil que incidem de maneira violenta sobre a população negra são fatores determinantes nos processos de adoecimento e morte, seja pelas situações de violência urbana, que no caso dos jovens negros assassinados configuram-se como genocídio; seja pela violência obstétrica que tem, entre suas vítimas preferenciais, as mulheres negras; seja no acolhimento institucional de crianças e adolescentes, majoritariamente negras(os), entre outras tantas formas de reprodução da violência étnico-racial. As marcas são visíveis. Remetem ao processo de escravidão e de uma abolição inconclusa nos termos de Chiavenato (1988), e para além disso, a violência étnico-racial tem sua função reformulada e continua a oferecer munição para manter a desigualdade social. Quer seja no âmbito do capitalismo mundial, cujas dimensões são globais, quer seja no da particularidade da vida brasileira, a verdadeira democracia racial configura-se um mito, contrária aos interesses do modo de produção vigente. A essa realidade soma-se as particularidades que compõem as relações étnico-raciais no país, indissociáveis da fragilidade da própria democracia brasileira. A primeira é absolutamente dependente da segunda e talvez esta seja a razão que mantém vivo o mito. A ação direta e contundente de homens e mulheres insatisfeitos com essa realidade provoca rupturas importantes que oxigenam os sonhos de uma sociedade melhor e as(os) profissionais de Serviço Social precisam se engajar também nessa frente de luta, pois o silêncio acerca dessa questão tão cara para a sociedade tem desdobramentos no trabalho cotidiano. Embora pareça óbvio, faz-se necessário pontuar que os sujeitos que acessam as políticas compõem-se de múltiplas dimensões: 
pertencimento étnico-racial, sexo, idade, identidade de gênero, orientação sexual e classe social. Dimensões essenciais e interdependentes, as quais, compreendidas em sua totalidade, ampliam as possibilidades de um fazer profissional pautado na ética e no respeito aos direitos humanos.

O combate ao racismo, ao preconceito e à discriminação étnico-racial exige, na mesma medida, o combate à sociedade de classes, à desigualdade de gênero, bem como o respeito à diversidade sexual, entre outras garantias individuais cotidianamente violadas. $\mathrm{O}$ debate está posto e cabe às(aos) profissionais se engajarem na luta contra todas as formas de exploração/ opressão, caminho indispensável rumo à efetivação do projeto ético-político profissional do Serviço Social, explicitado no Código de Ética de 1993, que dentre seus princípios reconhece a liberdade como valor ético central, propõe a defesa intransigente dos direitos humanos, o empenho na eliminação de todas as formas de preconceito e a não discriminação como princípios éticos fundamentais.

Recebido em 14/5/18 - Aprovado em 20/6/18

\section{Referências bibliográficas}

AMMA-PSIQUE E NEGRITUDE QUILOMBHOJE. Identificação e abordagem do racismo institucional. Brasil, 2008.

CASHMORE, E. et al. Dicionário de relações étnicas e raciais. Trad. Dinah Kleve. São Paulo: Selo Negro, 2000. DAVIS, A. Mulheres, raça e classe. Trad. Heci Regina Candiani. 1. ed. São Paulo: Boitempo, 2016. Declaração e Programa de Ação adotados na III Conferência Mundial de Combate ao Racismo, Discriminação Racial, Discriminação Racial, Xenofobia e Intolerância Correlata. Conferência de Durban. 31 de agosto a 8 de setembro de 2001, Durban — rica do Sul. Disp.

CHIAVENATO, J. J. As lutas do povo brasileiro: do "descobrimento" a Canudos. São Paulo: Moderna, 1988. 
EURICO, M. C. Questão racial e Serviço Social: uma reflexão sobre o racismo institucional e o trabalho do assistente social. Dissertação (Mestrado em Serviço Social). PUC/SP, São Paulo 2011.

IBGE. Censo demográfico 2010. Disponível em: <https://censo2010.ibge.gov.br/apps/ atlas/>. Acesso em: 1 fev. 2018.

IRACI, N.; SOVIK, L. Diálogos contra o racismo. Rio de Janeiro: Instituto Brasileiro de Análises Sociais e Econômicas (Ibase), dez. 2004.

JESUS, C. M. Quarto de despejo: diário de uma favelada. 10. ed. São Paulo: Ática, 1960.

LOPES, F.; QUINTILIANO, R. Racismo institucional e o direito humano à saúde. Democracia Viva, n. 34, jan./mar. 2007. Disponível em: http://www.ibase.br. Acesso em: 10 jan. 2016.

SANTOS, J. R. O que é racismo. São Paulo: Abril Cultural; Brasiliense, 1984.

SCHUCMAN, Lia Vainer. Sim, nós somos racistas: estudo psicossocial da branquitude paulistana. Revista Psicologia e Sociedade, 26 (1), 2014. Disponível em: $<\mathrm{http}: / / \mathrm{www}$. scielo.br/pdf/psoc/v26n1/10.pdf >. Acesso em: 17 fev. 2018.

\section{Nota da autora}

Márcia Campos Eurico - Mestre e doutora em Serviço Social pela PUC/SP, assistente social no INSS, docente na Faculdade Paulista de Serviço Social — FAPSS/SP e professora substituta na PUC/SP, Brasil.E-mail: marciamayza08@gmail.com 